\title{
Interannual variations and future change of wintertime extratropical cyclone activity over North America in CCSM3
}

\author{
Haiyan Teng • Warren M. Washington • \\ Gerald A. Meehl
}

Received: 15 March 2007/ Accepted: 29 August 2007/Published online: 7 November 2007

(C) Springer-Verlag 2007

\begin{abstract}
Climatology and interannual variations of wintertime extratropical cyclone frequency in CCSM3 twentieth century simulation are compared with the NCEP/ NCAR reanalysis during 1950-1999. CCSM3 can simulate the storm tracks reasonably well, although the model produces slightly less cyclones at the beginning of the Pacific and Atlantic storm tracks and weaker poleward deflection over the Pacific. As in the reanalysis, frequency of cyclones stronger than $980 \mathrm{hPa}$ shows significant correlation with the Pacific/North America (PNA) teleconnection pattern over the Pacific region and with the North Atlantic Oscillation (NAO) in the Atlantic sector. Composite maps are constructed for opposite phases of El Nino-Southern Oscillation (ENSO) and the NAO and all anomalous patterns coincide with observed. One CCSM3 twenty-first century A1B scenario realization indicates there is significant increase in the extratropical cyclone frequency on the US west coast and decrease in Alaska. Meanwhile, cyclone frequency increases from the Great Lakes region to Quebec and decreases over the US east coast, suggesting a possible northward shift of the Atlantic storm tracks under the warmer climate. The cyclone frequency anomalies are closely linked to changes in seasonal mean states of the upper-troposphere zonal wind and baroclinicity in the lower troposphere. Due to lack of 6-hourly outputs, we cannot apply the cyclone-tracking algorithm to the other eight CCSM3 realizations. Based on the linkage between the mean state change and the cyclone frequency anomalies, it is likely a common feature among the other
\end{abstract}

H. Teng $(\bowtie) \cdot$ W. M. Washington · G. A. Meehl

National Center for Atmospheric Research,

PO Box 3000, Boulder, CO 80307, USA

e-mail: hteng@ucar.edu ensemble members that cyclone activity is reduced on the East Coast and in Alaska as a result of global warming.

\section{Introduction}

In the boreal winter, extratropical cyclones are the major cause of severe weather in northern midlatitudes. As the public has become more aware of global warming and its possible impact on extreme weather, it becomes crucial to understand how the cyclone activity might change in the future.

In the recent Intergovernmental Panel on Climate Change (IPCC) Fourth Assessment Report (AR4) Summary for Policymakers, it says, "anthropogenic forcing is likely to have contributed to changes in wind patterns, affecting extra-tropical storm tracks and temperature patterns in both hemispheres". That statement is based on a number of general circulation model (GCM) studies. For example, Geng and Sugi (2003) showed a decrease of cyclone density and increase of strong cyclones in a highresolution atmospheric GCM. There are some indications that the storm tracks tend to shift poleward (Bengtsson et al. 2006), which is a robust feature in a 15-model ensemble (Yin 2005). After examining a set of scenarios and more than ten GCMs, Lambert and Fyfe (2006) concluded that the models in general produce a smaller number of cyclones and greater number of intense events as a result of greenhouse warming. However, these studies also suggest that the geographical pattern of the simulated change varies considerably among the models.

Global warming might suppress the extratropical cyclone activity by reducing baroclinicity in the lower troposphere. Development of extratropical cyclones highly 
depends on strong baroclinicity in midlatitudes, characterized by large meridional temperature gradient and low static stability. It has been widely accepted that under increased levels of greenhouse gases (GHGs), higher latitudes in the northern hemisphere experience more warming due to ice/snow/albedo feedback. Meanwhile, land is heated up faster than the ocean. Thus, both the meridional temperature gradient and land/sea contrast are reduced in the lower troposphere, implying weaker baroclinicity. On the other hand, in the upper troposphere the Tropics receives more warming than the higher latitudes, which enhances the meridional temperature gradient. In addition, the warmer air temperature due to global warming increases saturated vapor pressure and atmospheric humidity, which could enhance meridional latent heat fluxes and incubate stronger and more frequent cyclones. These competing effects add to the complexity of the link between the cyclone activity and global warming.

Some other controversies arise concerning how well the GCMs can capture variations of storm tracks in response to change in the mean state. Climatologically, the storm tracks are closely linked to the time-mean circulation (Blackmon et al. 1977, 1984; Hoskins and Valdes 1990, Lau 1988; and many others). On the interannual timescale, tropical heating anomalies associated with El NinoSouthern Oscillation (ENSO) shift the northern winter storm tracks near North America equatorward and downstream during the El Nino years (Trenberth and Hurrell 1994; Straus and Shukla 1997) and the opposite directions in the La Nina years. Significantly increased storm activity is found on the US east coast during the El Nino and the opposite in the La Nina years (Hirsch et al. 2001; Eichler and Higgins 2006). The Northern Atlantic Oscillation (NAO) can also affect the storm tracks over the Atlantic region (Rogers 1997; Hurrell and van Loon 1997; Serreze et al. 1997). Unfortunately, many GCMs devoted to simulating future change in the extratropical cyclones lack documentation on their ability to replicate the interannual variations.

Methods to measure cyclone activity generally fall into two categories. One is to use second-moment statistics of filtered meteorological variables, usually at mid- or uppertroposphere, to depict the geographical locations and intensity of the transients. The cyclone signals may be blended with high-frequency noise in the atmosphere. This method has been comprehensively used in diagnosing storm tracks during the early stage of GCM development, when accuracy of cyclone tracking could not be guaranteed due to the coarse model resolution.

The other choice is to detect cyclone centers (Serreze 1995; Serreze et al. 1997; Hodges 1994; Sinclair 1997; Simmonds and Keay 2000; Gulev et al. 2001; and many others), which is often followed by constructing cyclone trajectories. This Lagrangian approach can provide information on cyclone path, intensity, lifetime, and other useful statistics, which are more closely linked to regional climate extremes.

Criteria for cyclone identification and tracking algorithms vary from study to study. A simple version (e.g., Lambert and Fyfe 2006) only counts cyclones that have daily sea level pressure (SLP) lower than the four surrounding grids without tracking the cyclone's trajectory, which could accidentally take in thermal lows and other irrelevant SLP minima. More complicated methods also inspect SLP gradients, length of the life cycle, and/or minimum SLP during lifetime. There are other studies that investigate map projection problems (Zolina and Gulev 2002), resolution issues (Blender and Schubert 2000; Jung et al. 2006), and vorticity tracking (Sinclair 1997; Simmonds and Keay 2000; Rudeva and Gulev 2007; Greeves et al. 2007). Comparison of the different algorithms is generally lacking. Although more complicated or semiautomatic schemes are expected to be more reliable, simple methods (e.g., Lambert and Fyfe 2006) can nevertheless provide useful model diagnosis.

In this study, we choose a Lagrangian approach to investigate future change in the wintertime extratropical cyclone frequency in North America with Community Climate System Model Version 3.0 (CCSM3). In Sect. 2 we will describe the model, experiments, and the cyclone detection and tracking algorithm. Model cyclone climatology and interannual variability are compared with the NCEP/NCAR reanalysis in Sect. 3. Change in the twentyfirst century is discussed in Sect. 4. In Sect. 5, we will show that the future cyclone frequency anomalies are closely linked to change in large-scale mean flow and lower troposphere baroclinicity. The results are summarized in Sect. 6.

\section{Model, data and procedure}

\subsection{The coupled model}

CCSM3 (Collins et al. 2006) has four major components including the atmosphere, land, ocean and sea ice. Nine realizations have been performed for the twentieth century historical run and the A1B scenario in the twenty-first century (Meehl et al. 2006), and 6-hourly outputs have been saved for only one member. The historical runs are branched from the pre-industrial control run at different initial states. The external forcings include: sulfates, solar, volcanoes, ozone, greenhouse gases, and carbon aerosols.

Hurrell et al. (2006) have compared the model mean atmospheric circulation and interannual variability with the observations. The following biases have been found: the 
DJF mean SLP is higher than observed in the subtropics (the zonal mean difference is about $1.5 \mathrm{hPa}$ at near $30^{\circ} \mathrm{N}$ ), and is lower poleward of $50^{\circ} \mathrm{N}$; The upper-level westerly maxima associated with the main storm tracks over the Pacific and the Atlantic oceans are stronger than observed by about $5-10 \mathrm{~m} / \mathrm{s}$. The westerly jet over the North Atlantic also extends too far to the southeast resulting in a westerly bias of over $10 \mathrm{~m} / \mathrm{s}$ over Europe. The $200 \mathrm{hPa}$ eddy kinetic energy reveals that the model overestimates the northern winter storm tracks.

Alexander et al. (2006) took a Lagrangian approach to evaluate the CCSM3 storm tracks. They compared the cyclone trajectory counts in a CCSM3 present-day control run with the observations and found that the model produces fewer cyclones at both the beginning and end of the Pacific and Atlantic storm tracks. The model also underestimates the number of cyclones over the Mediterranean and in the lee of the Rocky Mountains. Cyclones at these two regions are mostly orographically induced and the cyclone numbers could be sensitive to the model resolution and the treatment of the orography in the model. Results from Hurrell et al. (2006) and Alexander et al. (2006) may not be contradictory because they target two different aspects of the storm tracks.

\subsection{Data and analysis methodology}

Our cyclone tracking algorithm is similar to Zhang et al. (2004), which was developed from Serreze (1995) and Serreze et al. (1997). The first step is to identify cyclone candidates that satisfy: the SLP at a grid point is lower than all eight surrounding points at $2.5^{\circ} \times 2.5^{\circ}$ lat/lon resolution; the SLP gradient between the cyclone candidate and its eight surrounding grids is no smaller than $0.15 \mathrm{hPa} /$ $100 \mathrm{~km}$. This threshold is considerably lower than Serreze (1995) and Serreze et al. (1997) that require a 2-hPa pressure drop between the cyclone center and the neighboring grids. Such change allows the method to capture the mid-latitude cyclones, which have smaller SLP gradients than the Arctic cyclones. Additional criteria include: the pressure gradient between the four surrounding grid points and their outside adjacent grid points must be negative inward; if there is more than one low pressure center within $1,200 \mathrm{~km}$, the grid point with lower SLP is considered as the cyclone candidate. After we identify a cyclone candidate, its location and time are saved. SLP animations with superimposed cyclone centers have been examined to ensure the accuracy of the screening.

The second step is to construct the cyclone trajectories. For each cyclone candidate, we search whether there is a cyclone center within a radius of $700 \mathrm{~km}$ at $6 \mathrm{~h}$ earlier. If there is one, the present cyclone's record (longitude, latitude, time, and SLP) will be added to the previous cyclone's trajectory. Otherwise, the cyclone will be considered as a new genesis. After we construct the trajectories, we further filter out the cyclones with less than eight records (lifetime shorter than 2 days). According to Gulev et al. (2001), about $20 \%$ of extratropical cyclones cannot survive two days. Here we use the 2-day threshold due to our interests in 2 to 8 -day synoptic-scale variability and its connection with the base sate. Exclusion of the short-lived cyclones also helps to avoid a large number of shallow cyclones, which are less well-defined and more difficult to track.

The NCEP-NCAR Reanalysis (Kalnay et al. 1996) is used to validate the model cyclones. The main cyclone characteristics in the NCEP-NCAR Reanalysis generally agree with the ERA-40 reanalysis, but it has also been noticed that the NCEP-NCAR Reanalysis may underestimate subsynoptic systems (Trigo 2005). CCSM3 6-hourly SLP outputs are first interpolated from T85 resolution to $2.5^{\circ} \times 2.5^{\circ}$ lat/lon, same as the NCEP-NCAR reanalysis. Although in general, reducing the spatial resolution may decrease the total number of detected cyclones (Blender and Schubert 2000), the interpolation facilitates direct comparison with the reanalysis. Our study mainly focuses on the mid-latitudes south of $70^{\circ} \mathrm{N}$. Great circle distance is used in calculating the SLP gradient and measuring distance for other purposes, which provides adjustment of the latitudinal variation of the grid size. January to March is chosen to represent the northern winter season and cyclone frequency is defined as the total number of cyclone trajectory counts during that period. The cyclone frequency will be presented either on $5^{\circ} \times 5^{\circ}$ lat/lon grids to facilitate comparison with some previous studies, or on the $2.5^{\circ} \times 2.5^{\circ}$ original search grids. Amplitudes of the frequency on the $2.5^{\circ} \times 2.5^{\circ}$ grids are about one-fourth of those on the $5^{\circ} \times 5^{\circ}$ grids.

\section{Interannual variations of the extratropical cyclone frequency}

The CCSM3 JFM cyclone frequency climatology during 1950-1999 generally coincides with the reanalysis (Fig. 1 a, b), despite the fact that the model produces slightly fewer cyclones at all three major cyclone activity centers, which is in agreement with Alexander et al. (2006). Over the North Pacific, the storm track tilts from Japan northeastward to Aleutian Islands in the reanalysis, whereas it is more zonally oriented in CCSM3. The reanalysis also shows a secondary cyclone center in Gulf of Alaska, which is missing in CCSM3. Hurrell et al. (2006) showed the eddy kinetic energy of the storm tracks are more zonally elongated in Community Atmosphere Model Version 3 
Fig. 1 a, b Climatological winter cyclone frequency (events/winter per $5^{\circ} \times 5^{\circ}$ lat/ lon degree) in the Reanalysis and the CCSM3 historical run, respectively. c, d Climatological winter frequency of cyclone generation (percent of the total number of cyclones) in the Reanalysis and CCSM3, respectively
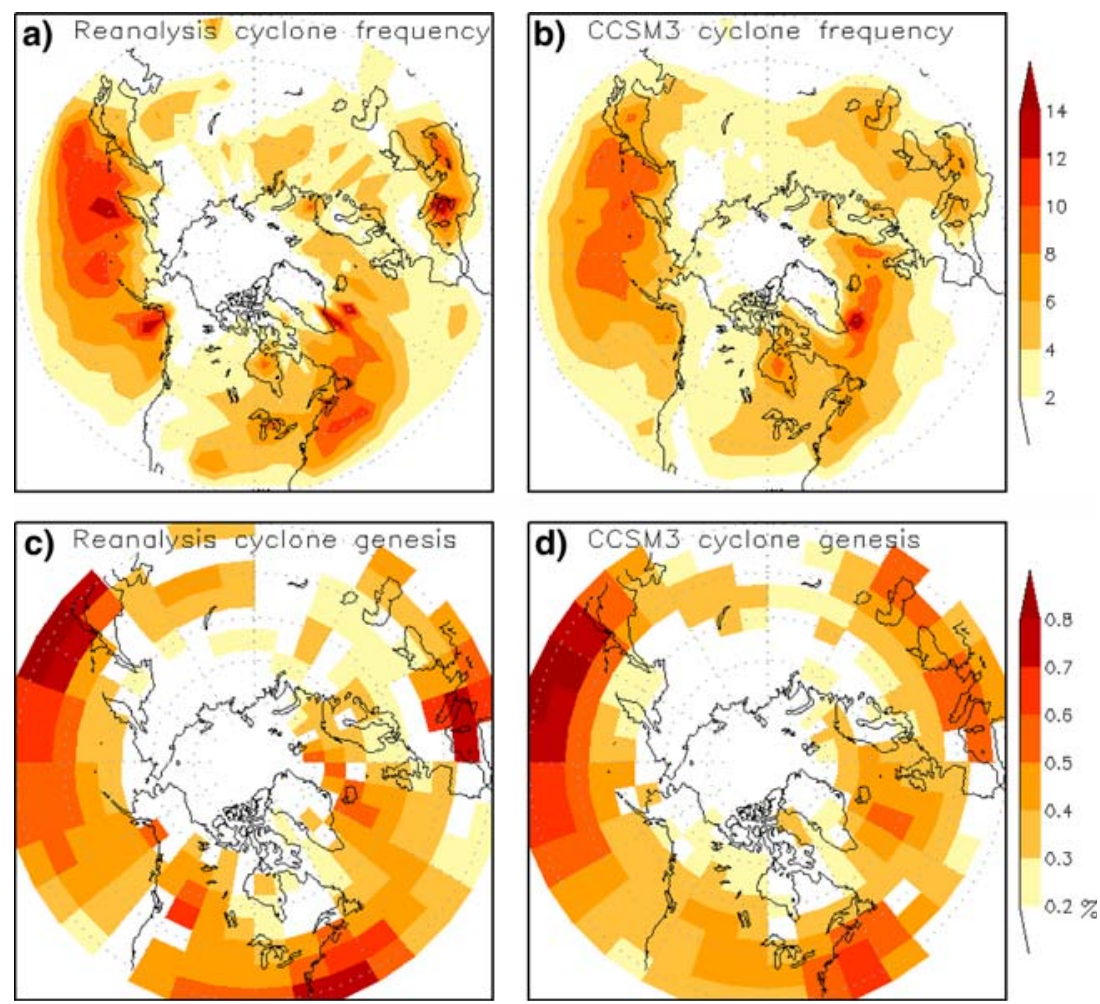

(CAM3), the atmosphere component of CCSM3. Orlanski (1998) revealed the combined effect of eddy meridional momentum fluxes and the difference in the variance of eddy $v$ velocity minus $u$ velocity can tilt the storm track into a southwest-northeast orientation. His theory may help to further diagnose why the model lacks poleward deflection of the storm tracks. Over the Atlantic region, the model storm tracks are narrower with fewer cyclones at the entrance region. In addition, the reanalysis suggests a frequent cyclone path from the US southern Great Plains to the Great Lakes region, which is less obvious in CCSM3. This feature has also been documented by Alexander et al. (2006).

Our climatology (Fig. 1a, b) is slightly lower than Gulev et al. (2001), which is partly due to the fact that we have excluded cyclones that have a lifespan shorter than 2 days. Alexander et al. (2006) have examined the cyclone frequency using daily outputs (from a CCSM3 present day control run) with a different cyclone tracking method. Although our cyclone frequency climatology (Fig. 1a, b) is a little larger than Alexander et al. (2006), both reveal similar model biases.

On average, our tracking scheme yields 204 extratropical cyclones in the reanalysis data during January to March and 198 in the CCSM3. The numbers are about $15 \%$ less than Gulev et al. (2001). Cyclogenesis frequency patterns are similar in both the reanalysis and CCSM3 (Fig. 1c, d), with the maxima located over Kuroshio, on the East Coast of North America and in the eastern Mediterranean, except that the location of the maxima shifts slightly downstream. Compared to Gulev et al. (2001), we have larger cyclogenesis frequency over the Mediterranean and less to the east of Greenland. The change can be caused by different criteria used for cyclone tracking. Gulev et al. (2001) set the lifespan threshold to $12 \mathrm{~h}$ and have excluded cyclones that have not grown lower than $1,000 \mathrm{hPa}$ throughout the life cycle.

Statistics of cyclone intensity, lifespan, and deepening/ filling rates are presented in Fig. 2. Cyclone intensity is defined as the minimum SLP during the cyclones' lifetime. A latitudinal adjustment (sine function) of the SLP anomalies was used to calculate the deepening/filling rates as in Gulev et al. (2001). Averaged cyclone intensity is 986.7 $\mathrm{hPa}$ in the reanalysis and $979.2 \mathrm{hPa}$ in the CCSM3 (Fig. 2a), and the difference is probably caused by the bias in CCSM3 SLP mean field (Hurrell et al. 2006). Statistics of lifetime and deepening/filling rates are similar in the two datasets, except that the model slightly underestimates some rapid deepening/filling events.

Comparison of Fig. 2 with Gulev et al. (2001) suggests that our histogram drops more abruptly when the lifetime changes from 2 to 3 days. Similar abrupt decrease is also found in other automatic tracking results (Fig. 5, Jung et al. 2006). Underestimation of cyclone lifetime is considered a systematic error in automated cyclone tracking schemes (Gulev et al. 2001). In this study, we use a radius of $700 \mathrm{~km}$ 
Fig. 2 Winter climatological occurrence histograms of a cyclone intensity, b lifetime, and $\mathbf{c}$ deepening/filling rates. The red color represents the Reanalysis and the blue is for CCSM3
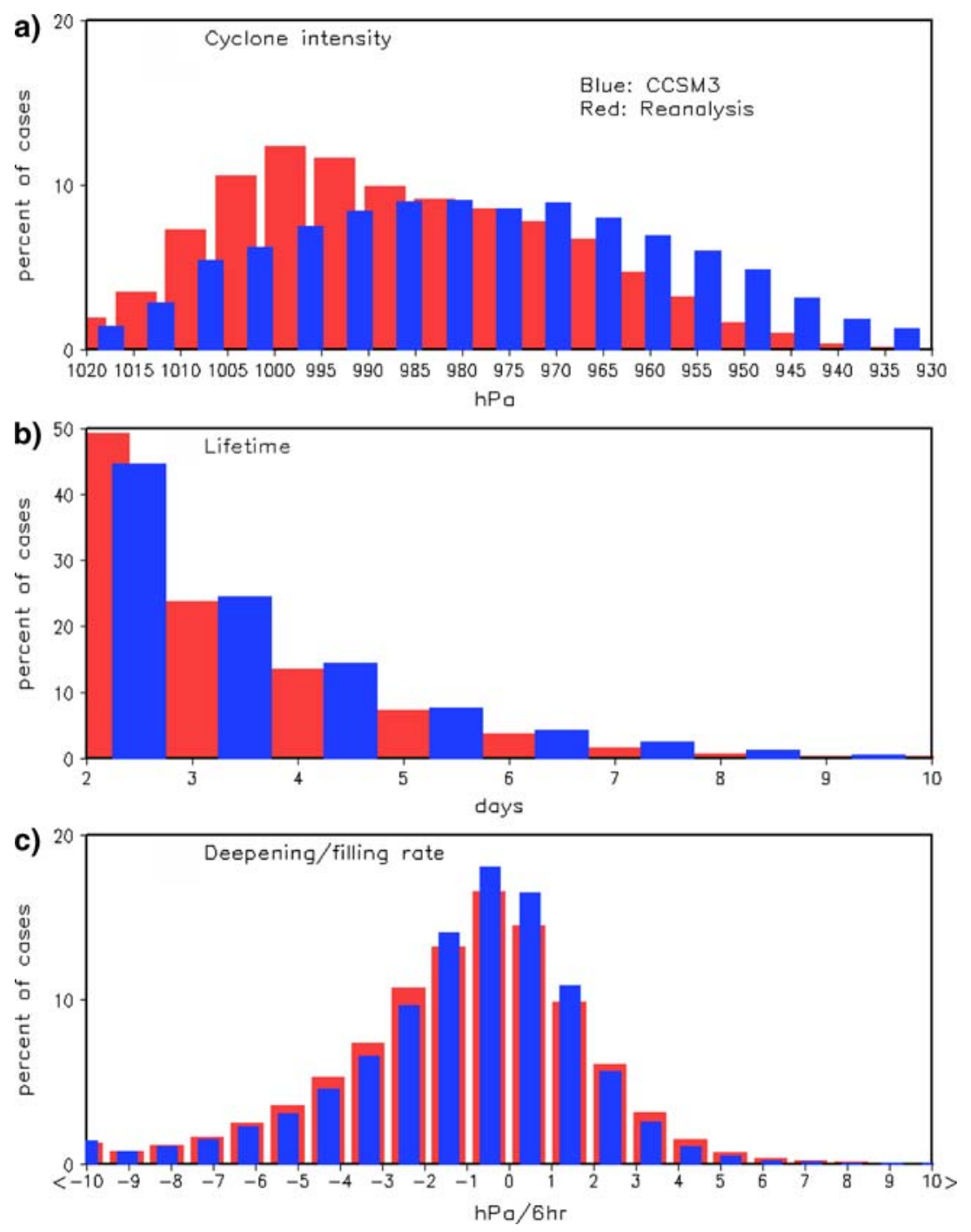

within $6 \mathrm{~h}$ to define whether a cyclone is a newborn. Based on the analysis of the cyclone size and maximum speed (Rudeva and Gulev 2007), a small percentage of lowpressure centers could be developed outside this radius at $6 \mathrm{~h}$ later. Increasing the threshold may mix two existing cyclones' trajectories. A similar dilemma is faced by all automated storm-tracking schemes.

In the next section, we will show how cyclone lifetime changes under the warmer climate. Although some significant differences are found in the twenty-first century, we must be aware of the caveats that must accompany the automated tracking. On the other hand, automated schemes can still be a useful approach, especially for modeling studies that require processing a large amount of data. Application of the same automated scheme to two parallel datasets can effectively reveal the difference, in spite of possible miscalculations regarding whether a cyclone candidate belongs to an existing cyclone or is a newborn. For instance, although our study employs a very different algorithm from Alexander et al. (2006), both revealed similar model biases in the cyclone frequency.

Similar to Gulev et al. (2001), frequency of strong cyclones (SLP lower than $980 \mathrm{hPa}$ ) is positively correlated with the Pacific/North America teleconnection pattern (Wallace and Gutzler 1981) in the Pacific region and the North Atlantic Oscillation (Hurrell 1995) over the Atlantic sector (Fig. 3). The correlation coefficients are less significant (the $95 \%$ significance level is about 0.3 ) between the frequency of cyclones of all intensities and the indices. We have also applied EOF analysis to the frequency of cyclones of all intensities. The first principal component for the Pacific/Atlantic sectors confirms the above relationship, except that the explained variance is much lower than Lau (1988), who applied EOF analysis to a circulation variable.

The relationship between the cyclone frequency and ENSO is assessed using composite charts of strong El Nino and La Nina years, which are defined by the absolute values of the 1 to 5-year filtered DJF Nino34 SST 
Fig. 3 a Linear correlation coefficients between the PNA index and the frequency of cyclones deeper than $980 \mathrm{hPa}$ in the Reanalysis for the period 1950-1999, and b same as a but for CCSM3, c same as a but for linear correlation coefficients with the NAO index in the Atlantic sector, and $\mathbf{d}$ same as $\mathbf{c}$ but for CCSM3. Unit of the cyclone frequency is events/ winter per $5^{\circ} \times 5^{\circ}$ lat/lon degree. The $95 \%$ significance level for the correlation coefficients is about 0.3

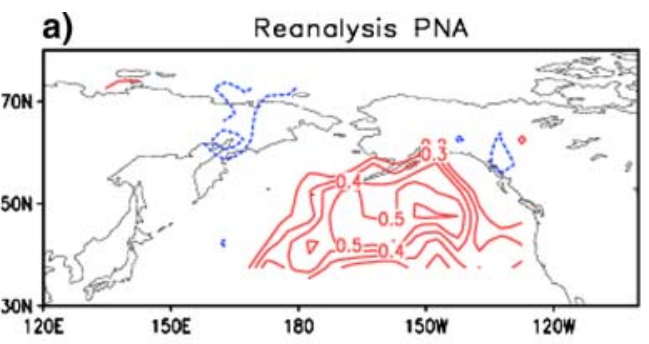

c)

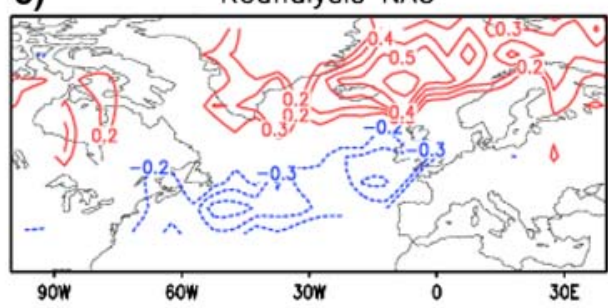

b) CCSM3 PNA

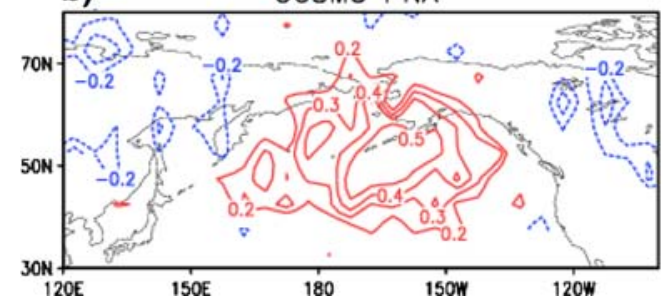

d)

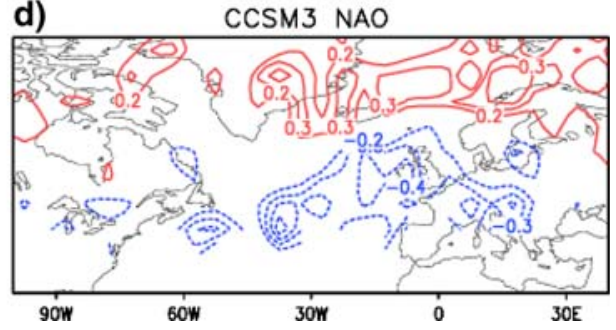

anomalies exceeding 1 standard deviation. We chose the 1 to 5-year window because both the observations and the model exhibit strong interannual variability within this band and it can also remove the trend in the index. During the El Nino winters, more cyclones are found over the Aleutian Islands and the eastern North Pacific in both observations and the model (Fig. 4a, c). Enhanced storm activity in these regions is associated with anomalous Rossby wave response from convective heating anomalies in the tropical Pacific resulting in an anomalously deepened Aleutian low-pressure center and consequent storm activities in that region. There is an opposite pattern during the La Nina winters (Fig. 4b, d). Other features include a southward displacement of the cyclone trajectories between $160^{\circ} \mathrm{W}$ and $130^{\circ} \mathrm{W}$ at the Pacific storm track exit region, and a southward displacement of the Atlantic storm track on the east coast during El Nino. The latter anomalies in the Atlantic region are less robust in the model, as has been noticed by Alexander et al. (2006).

Similarly, strong positive and negative NAO events are defined as years with absolute values of the 1 to 5-year filtered NAO index exceeding 1 standard deviation. In both the observations and the model, cyclone frequency anomalies at the extreme phases of the NAO are featured by a dipole pattern with one polarity zonally elongated from the US east coast to the Mediterranean and the other polarity confined to the Arctic region. During the positive NAO years, in response to the deepened Icelandic low, the storm tracks extend northeastward to the Norwegian and Barents Seas (Fig. 5a, c). Meanwhile, storm activity weakens in the subtropical Atlantic and Europe due to the intensified subtropical high. The anomalies reverse sign in the negative NAO years (Fig. 5b, d). These patterns are consistent with previous observational studies (Rogers 1997).
Fig. 4 a, b JFM cyclone frequency composite for 11 strong El Nino years and nine strong La Nina years in NCEP/ NCAR Reanalysis, respectively. c, $\mathbf{d}$ same as a and $\mathbf{b}$ except for 11 strong El Nino years and 10 strong La Nina years in CCSM3, respectively. Shading indicates significant population difference at the $90 \%$ confidence level. Unit of cyclone frequency is events/ winter per $2.5^{\circ} \times 2.5^{\circ}$ lat/lon degree. Nine-point smoothing has been applied
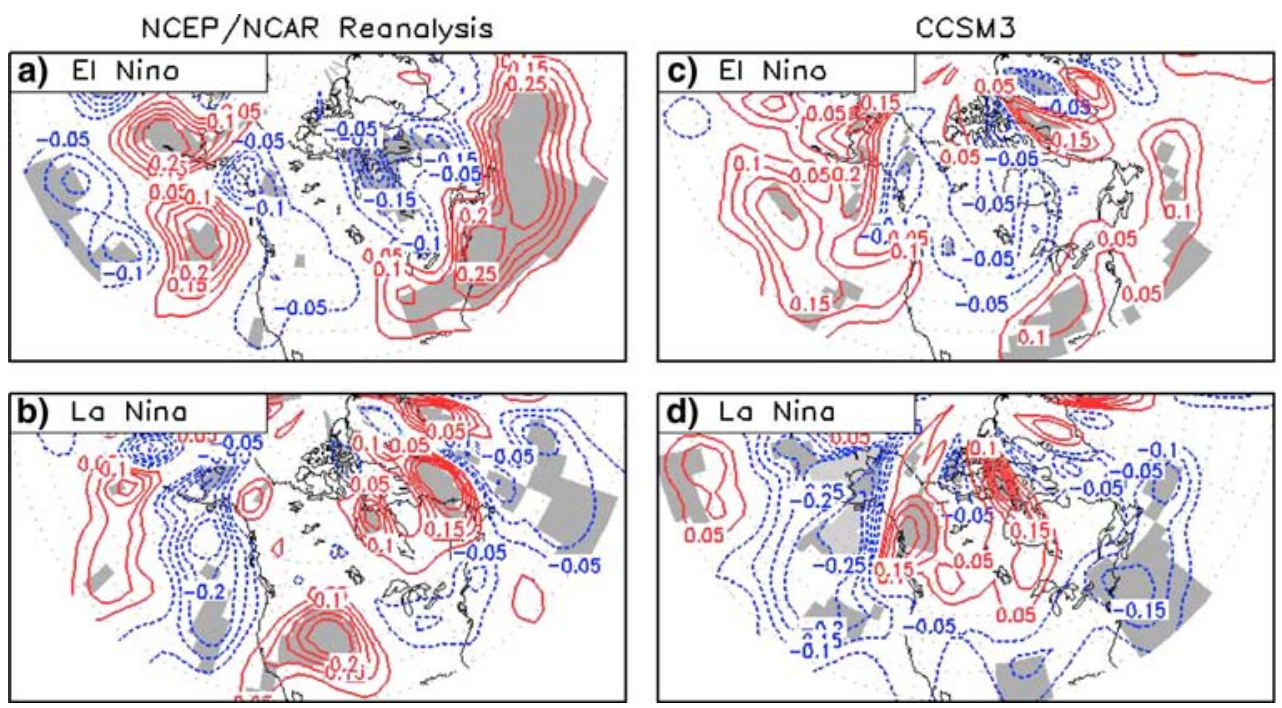
Fig. 5 a, b JFM cyclone frequency composite for nine strong positive NAO years and eight negative NAO years in NCEP/NCAR Reanalysis, respectively. c, d Same as a and b except for seven strong positive NAO years and seven negative NAO years in CCSM3, respectively. Shading indicates significant population difference at the $90 \%$ confidence level.

Unit of the cyclone frequency is events/winter per

$2.5^{\circ} \times 2.5^{\circ}$ lat/lon degree.

Nine-point smoothing has been applied
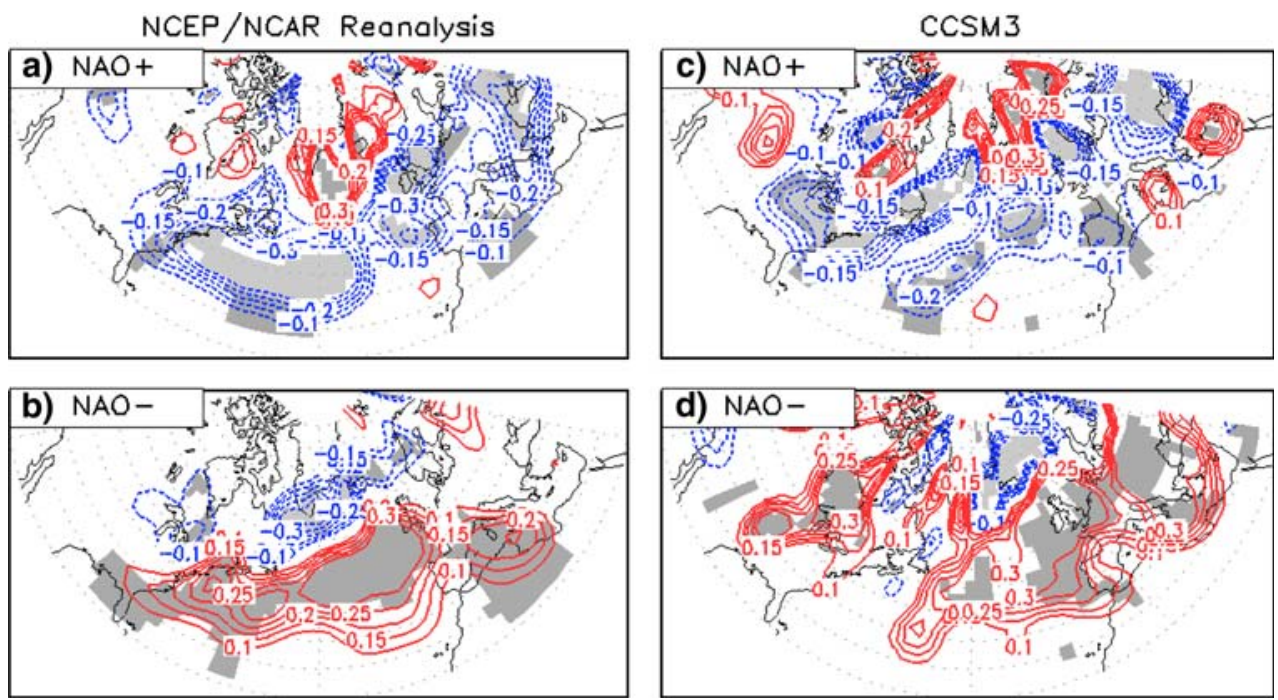

Several earlier studies have examined trends in cyclone activity in the observations. The trends can be strongly influenced by decadal variability (reviewed by Chang at al. 2002) or the upward trend in the NAO from 1980s to early 1990s. Because the interdecadal variability in the CCSM3 historical runs is not expected to be in phase with the observations and the model lacks the observed upward trend in the NAO (Teng et al. 2006a), we are not surprised to find the model trend during 1950-1999 is different from the reanalysis.

\section{Future change in cyclone frequency under the A1B scenario}

We first look at Northern Hemisphere zonal totals/means regarding cyclone genesis, lifetime, cyclone trajectory count and intense cyclone trajectory count to provide some broad information. Figure 6a shows the zonal total numbers of cyclone genesis averaged in 1980-1999 and 20802099 (the latter for the A1B scenario). At the end of the twenty-first century, fewer cyclones are generated between $35^{\circ} \mathrm{N}$ and $55^{\circ} \mathrm{N}$ while slightly more cyclones are initiated in the Arctic. We have also grouped the cyclone trajectory counts by latitude of genesis and calculated the zonally averaged cyclone lifetime (Fig. 6b). Cyclones tend to have a longer life span regardless of where they are generated. Most significant changes are found at $35^{\circ} \mathrm{N}-45^{\circ} \mathrm{N}$ and $65^{\circ} \mathrm{N}-72.5^{\circ} \mathrm{N}$, where cyclone lifetime is increased by several hours under the warmer climate.

Total cyclone trajectory count (Fig. 6c) is affected by both the genesis number and the cyclone life span. Although the cyclones tend to survive longer, because fewer cyclones are generated in the midlatitudes, the total cyclone trajectory count decreases at $40^{\circ} \mathrm{N}-55^{\circ} \mathrm{N}$ in 2080
2099 compared with $1980-1999$. North of $60^{\circ} \mathrm{N}$, both increased cyclone genesis and longer life span build up the total cyclone trajectory count.

We also sort out intense cyclones, which are those with the central pressure lower than $970 \mathrm{hPa}$ (we use $980 \mathrm{hPa}$ in Fig. 3 to facilitate comparison with Gulev et al. 2001). The zonal intense cyclone trajectory count (Fig. 6d) shows a decrease between $35^{\circ} \mathrm{N}$ and $42.5^{\circ} \mathrm{N}$ and an increase in the Arctic in the twenty-first century. The amplitude of the increase in the Arctic is more pronounced than the decrease in the subtropical region.

As a summary, in the twenty-first century there are slightly less extratropical cyclones in the midlatitudes. This is in agreement with Geng and Sugi (2003) and Bengtsson et al. (2006). Additionally, there are more cyclones at high latitudes, which is consistent with the previous study (Yin 2005) that found a northward shift of the storm tracks using an Eulerian approach. A new finding here is that the cyclones tend to have longer life span under the warmer climate. Our result regarding the intense cyclones is different from Bengtsson et al. (2006): the trajectory count of the intense storms decreases between $35^{\circ} \mathrm{N}$ and $42.5^{\circ} \mathrm{N}$ and increases in the Arctic in the CCSM3, while there is no indication of more intense storms either in the Tropics or extratropics in the European Centre/Hamburg Model Version 5 (ECHAM5). Because the cyclone frequency anomalies exhibit large regional variations at the same latitude, caution is required when applying these general results to a specific region.

Horizontal distribution of the cyclone frequency anomalies over North America in 2080-2099 relative to 1980 1999 is presented in Fig. 7. Cyclone frequency is increased on the west side of the continent and the adjacent ocean from British Columbia to the western US. Meanwhile, lessfrequent cyclones are found in Gulf of Alaska. The east 
Fig. 6 Model climatology for the end of the twentieth century (1980-1999 average, dashed) and end of the twenty-first century (2080-2099, solid) for A1B scenario for a zonal total number of cyclone genesis, b averaged cyclone lifetime varying with the latitude where the cyclone is generated, $\mathbf{c}$ zonal total cyclone trajectory count and $\mathbf{d}$ zonal total intense cyclone (central pressure $<970 \mathrm{hPa}$ ) trajectory count. The black dots indicate significant population difference at the $90 \%$ confidence level
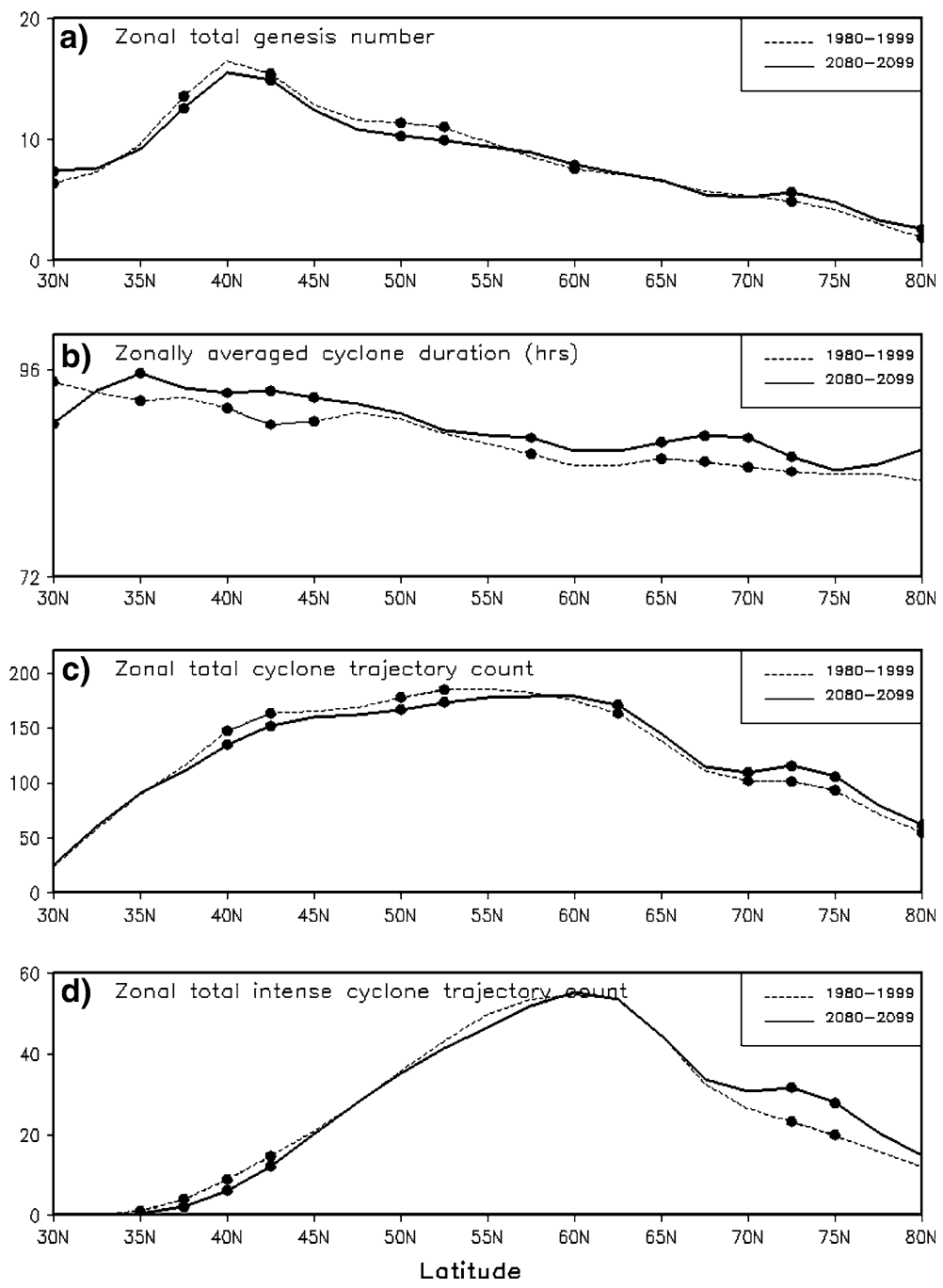

side of the continent is characterized by a band of negative anomalies titling from the US east coast to west of Ireland, adjacent to a band of positive anomalies stretching from the Great Lakes region to both east and west sides of Greenland.

In addition, the interannual variability in cyclone frequency increases/decreases on the west/east side of the continent in the twenty-first century. Three 50-year time series of the cyclone trajectory count are constructed on the US west coast at $240^{\circ} \mathrm{E}-250^{\circ} \mathrm{E}, 32.5^{\circ} \mathrm{N}-47.5^{\circ} \mathrm{N}$ and East
Coast at $280^{\circ} \mathrm{E}-295^{\circ} \mathrm{E}, 32.5^{\circ} \mathrm{N}-5^{\circ} \mathrm{N}$ (Fig. 8). The period spans from year 1950 to 1999 for both the CCSM3 twentieth century run and the NCEP/NCAR reanalysis, and 2050-2099 for the CCSM3 A1B scenario. At both domains, the difference between the averages over the two simulated time periods is significant at the $90 \%$ level. It is noted that the change in the averaged cyclone trajectory count between the two periods is more likely caused by more or less extreme years rather than a uniform shift in the mean cyclone trajectory count.
Fig. 7 JFM cyclone frequency anomalies averaged over 2080 2099 relative to $1980-1999$. Shading indicates significant population differences at the $90 \%$ confidence level. Unit of cyclone frequency is events/ winter per $2.5^{\circ} \times 2.5^{\circ}$ lat/lon degree. Nine-point smoothing has been applied

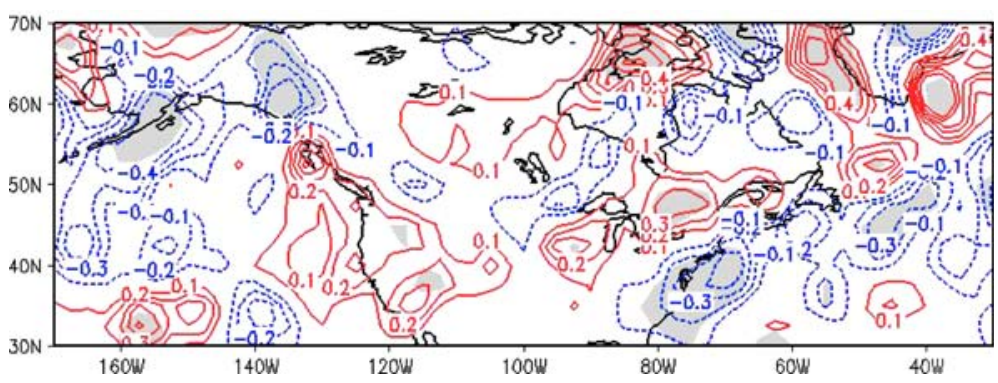




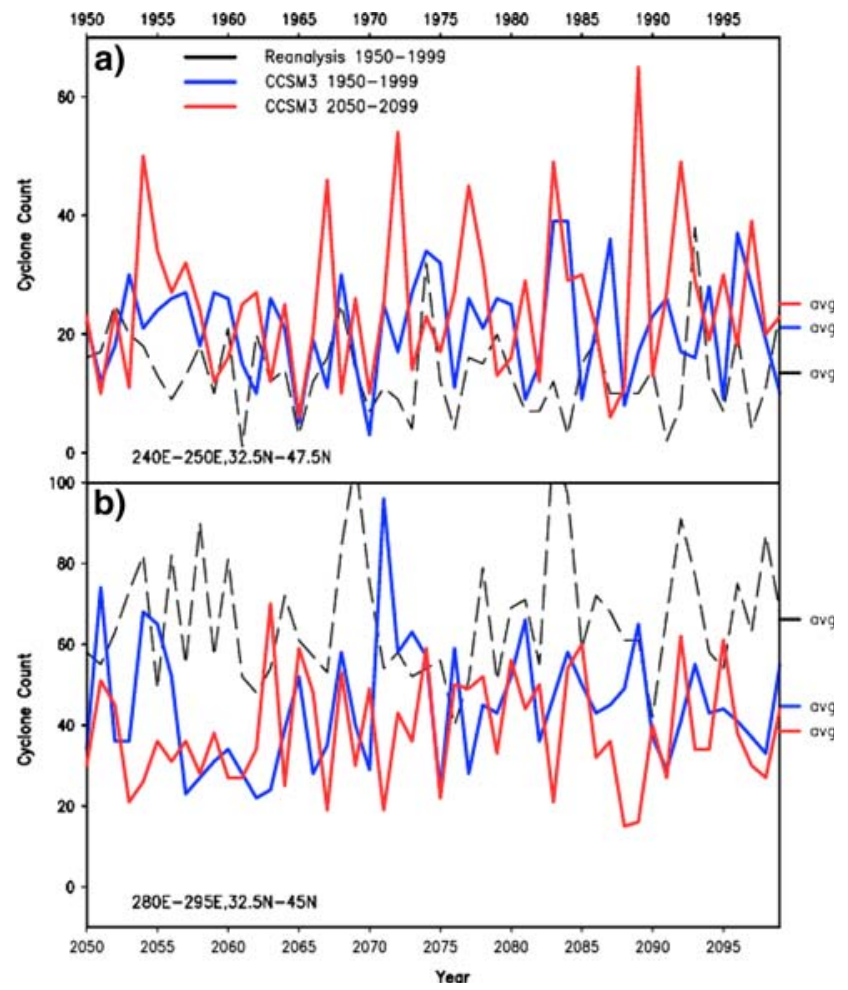

Fig. 8 JFM cyclone trajectory count summed over a $240^{\circ} \mathrm{E}-250^{\circ} \mathrm{E}$, $32.5^{\circ} \mathrm{N}-47.5^{\circ} \mathrm{N}$ and $\mathbf{b} 280^{\circ} \mathrm{E}-295^{\circ} \mathrm{E}, 32.5^{\circ} \mathrm{N}-45^{\circ} \mathrm{N}$ over the period of 1980-1999 for the Reanalysis, 1980-1999 and 2080-2099 for the CCSM3. The blue and red lines represent the CCSM3 simulations during 1950-1999 and 2050-2099, respectively, and the black line denotes the reanalysis data during 1950-1999

The cyclone tracking results are compared with those from eddy kinetic energy (EKE) analysis. The 2 to 8-day bandpass filtered EKE anomalies during January to March 2080-2099 relative to 1980-1999 are presented in Fig. 9. At the $300 \mathrm{hPa}$ level, North America is characterized by suppressed/enhanced EKE to the south/north of about $50^{\circ} \mathrm{N}$. The $500 \mathrm{hPa}$ level shows a similar negative EKE anomaly band in the midlatitudes except that there are no significant positive anomalies at the higher latitudes. The negative EKE anomaly band in the mid- and upper-troposphere splits into two parts at the $850 \mathrm{hPa}$ level: one over the North Pacific and the other on the US east coast. There are some positive anomalies in the Labrador Sea but no significant EKE changes are found over the North America continent.

Both methods agree that cyclone activity on the US east coast is suppressed at the end of the twenty-first century, but disagree on the West Coast and the Great Lakes region. These results may not be contradictory because the Eulerian and Lagrangian approaches focus on different aspects of the storm activity. In order to better understand the anomalous cyclone frequency pattern in the twenty-first century, we need to further investigate change in the mean states due to greenhouse gas forcing.

\section{Linkage with change in the base state}

At the storm track entrance region, cyclone growth is dominated by baroclinic conversion resulting from strong meridional and land/ocean temperature gradients in the midlatitudes. However, further down the storm tracks, energy fluxes from upstream becomes more important for eddy development (Chang et al. 2002). Change in the mean flow can have direct impacts on the downstream eddies.

Cyclone activity in the eastern Pacific and on the US west coast may be affected by a systematic shift of the upper level jet stream. Figure 10a shows the $300 \mathrm{hPa}$ zonal wind averaged over the period 1980-1999. The main oceanic storm tracks off the east coast of Asia and North America are characterized by the strongest zonal wind. For the future anomalies (Fig. 10b), over the Pacific, the jet exit region has larger negative anomalies compared to the jet core region in the western North Pacific. Negative anomalies in the North Pacific and positive anomalies in the subtropics suggest that the jet exit shifts southward and eastward. Over the Atlantic, positive anomalies on Canada's east coat and negative anomalies on the US east coast indicate a northward shift and an eastward extension. Because the jet plays an important role in transporting kinetic energy and moisture downstream, the southward shift and eastward extension of the Pacific jet stream favor cyclone development on the US west coast.

Genesis and maintenance of the extratropical cyclones require large baroclinicity in the atmosphere. According to Lindzen and Farrell (1980) and Hoskins and Valdes (1990), Eady growth rate maximum at $780 \mathrm{hPa}$ can provide a suitable measure of baroclinicity. It is defined as: $\sigma_{\mathrm{BI}}=$ $0.31 f|\partial \mathbf{V} / \partial Z| N^{-1}$, where 0.31 is a nondimensional coefficient, $f$ is the Coriolis parameter, $N$ is Brunt-Väisälä frequency, $\mathbf{V}$ is zonal wind and $Z$ is height. This baroclinic parameter has been widely used by storm track studies.

Future change in the $780 \mathrm{hPa}$ Eady growth rate maximum (Fig. 11) carries similar spatial patterns as the $300 \mathrm{hPa}$ zonal wind anomalies (Fig. 10b). The Pacific is characterized by weakened baroclinicity at $40^{\circ} \mathrm{N}-50^{\circ} \mathrm{N}$, sandwiched by strengthened baroclinicity in the Arctic and the subtropical eastern Pacific, respectively. In the Atlantic sector, negative anomalies dominate the Gulf Stream regions. Over the continent, positive anomalies prevail from the Great Lakes region to Canada's east coast. There are also positive anomalies in the southern Great Plains.

Comparing Figs. 7 and 11, we find that the future change in the cyclone frequency is closely related to change in the upstream baroclinicity parameter. Typical cyclone tracks show most cyclones originate in the North Pacific, the subtropical eastern Pacific, and the southeastern US and the Atlantic Gulf Stream region, respectively, before they travel to Alaska, the western US and the upper 
Fig. 9 Eddy kinetic energy anomalies in JFM 2080-2099 relative to 1980-1999 at a $300 \mathrm{hPa}, \mathbf{b} 500 \mathrm{hPa}$ and c $850 \mathrm{hPa}$. Stippling indicates at the $90 \%$ confidence level significant population difference
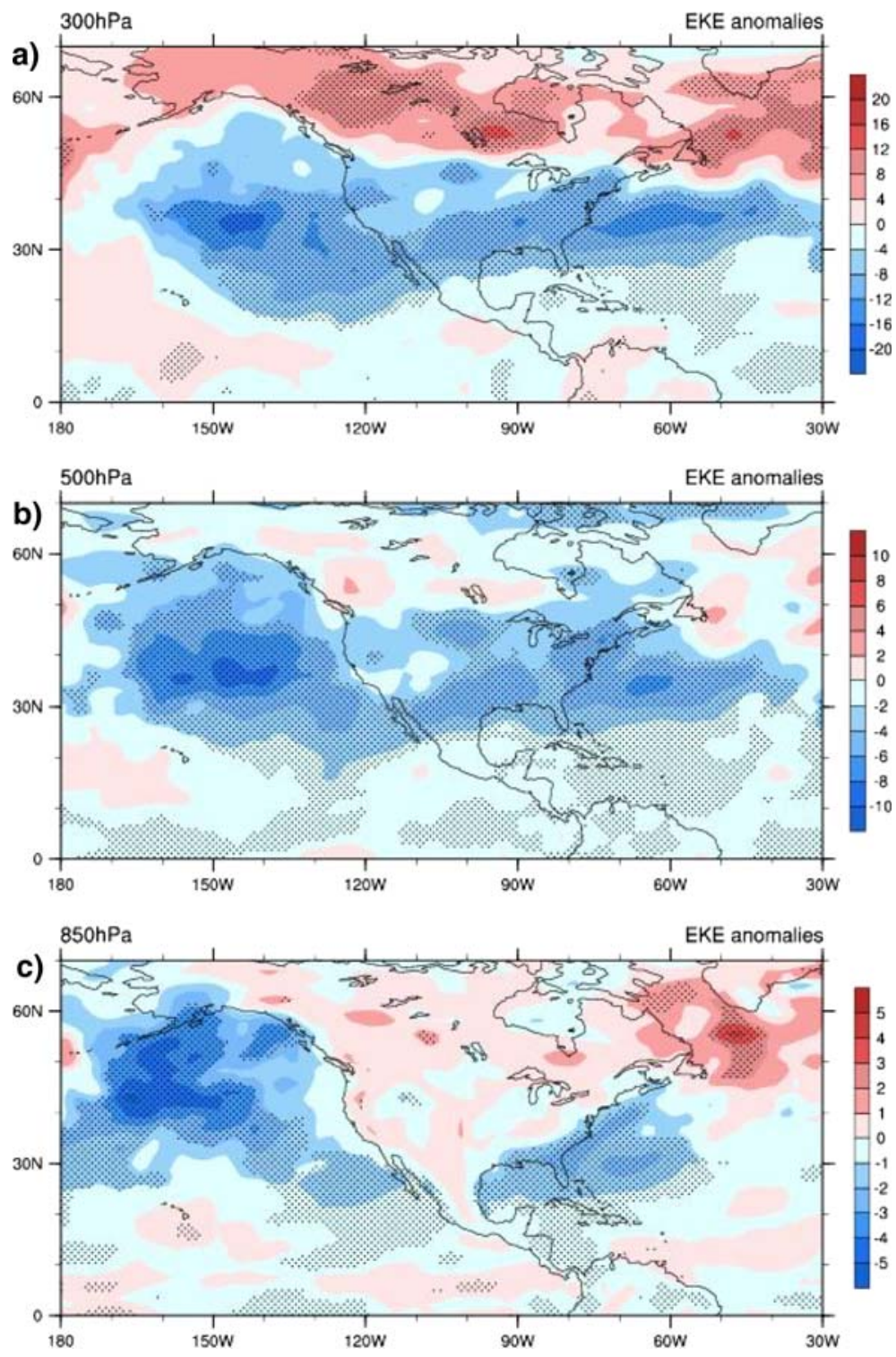

states on the US east coast (e.g., Bengtsson et al. 2006; Fig. 1). Cyclones in the Great Lakes region often have passed either the southern Great Plains or West Canada, with both regions showing higher baroclinicity at the end of the twenty-first century (Fig. 11).

There are uncertainties associated with analyzing only one realization and it could be called into question whether the above results are general features in all CCSM3 runs. As we have mentioned earlier, there are nine ensemble members available for both the twentieth century and the twenty-first century A1B runs, but only one member provides 6-hourly outputs. Using daily outputs for storm tracking may induce considerable inaccuracy (Blender and Schubert 2000) and is therefore not desired. However, the comparatively good agreement between changes in cyclone frequency and the mean state in the upper troposphere zonal flow or lower troposphere Eady growth rate maximum allows us to speculate regarding the future change in cyclone frequency using seasonal means.

The nine-member ensemble mean anomalies in JFM $300 \mathrm{hPa}$ zonal wind (compare to the single member in Fig. 10) and $780 \mathrm{hPa}$ Eady growth rate maximum (compare to the single member in Fig. 11) are presented in Fig. 12. Over the Pacific Ocean, most other members also produce suppressed baroclinicity in the North Pacific and enhanced baroclinicity in the subtropical eastern Pacific, accompanied with a southward shift and an eastward extension of the Pacific westerly jet. Over the Atlantic, the nine-member mean $300 \mathrm{hPa}$ zonal wind anomalies are characterized by enhanced westerlies across the Caribbean extending to the subtropical Atlantic, which is different from the one member that we have shown above (Fig. 10). Lack of significant signals at the higher latitudes suggests relatively large deviations among the ensemble members. 
Fig. 10 JFM $300 \mathrm{hPa}$ a mean zonal wind in 1980-1999 and b mean zonal wind anomalies in 2080-2099 relative to 19801999. The unit of both panels is $\mathrm{m} / \mathrm{s}$. Shading indicates significant population difference at the $90 \%$ confidence level

Fig. 11 The 780 hPa Eady growth rate maximum (1/day) anomalies in JFM 2080-2099 relative to 1980-1999. Shading indicates significant population difference at the $90 \%$ confidence level
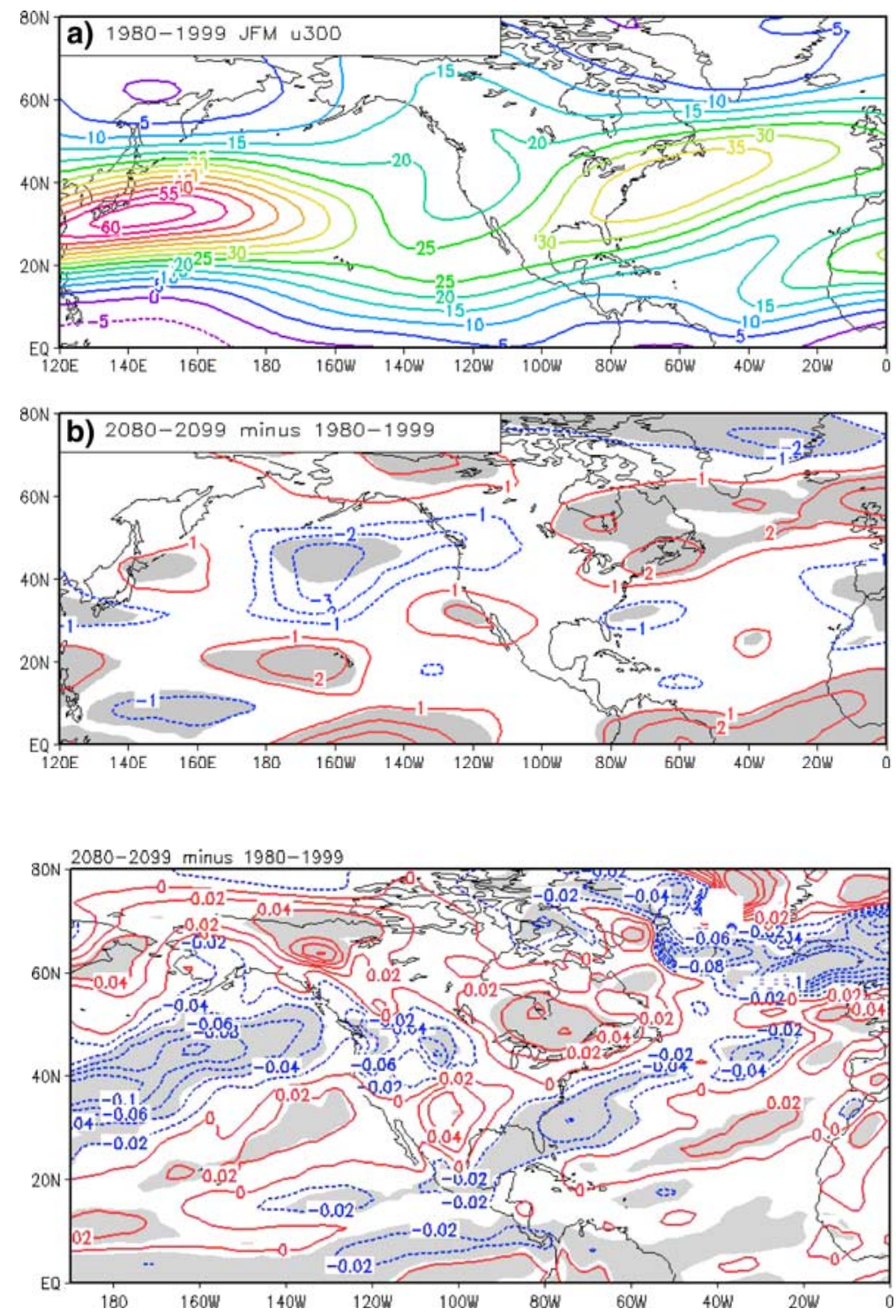

Compared to the $300 \mathrm{hPa}$ zonal wind, there is better agreement on the future change in the lower-troposphere baroclinicity (Fig. 12b) between the multi-members and the single member (Fig. 11). It is weakened in the north Pacific, the western North Atlantic and most of the North America continent except in the US southern Great Plains.

The nine-member ensembles support the previous finding that greenhouse gas warming may reduce wintertime cyclone frequency in Alaska and on the East Coast. It also confirms that baroclinicity is increased in the southern Great Plains, which is probably due to the combined effect of an enhanced upper-level jet stream and topography. However, with suppressed baroclinicity prevailing over Canada and most of the US, the other members do not agree with the one realization on more frequent cyclones in the Great Lakes region. Compared to the US east coast and Alaska, there are more uncertainties in the western US.
Although the extended upper-troposphere westerlies may bring more moisture and eddies from the eastern Pacific, they are offset by reduced local baroclinicity. However, we need to point out that our interpretation is based on the linkage between the mean state change in $300 \mathrm{hPa}$ zonal mean flows and the $780 \mathrm{hPa}$ baroclinicity. Eddy energy budget analysis is needed in order to quantify contributions from different physical processes.

\section{Conclusions}

In order to assess future changes in extratropical cyclone frequency over North America in the CCSM3 A1B scenario, we have first compared the cyclone frequency climatology and interannual variations with the reanalysis data. Consistent with the observations, frequency of 
Fig. 12 Nine-member ensemble mean a $300 \mathrm{hPa}$ zonal wind anomalies and $\mathbf{b} 780 \mathrm{hPa}$ Eady growth rate maximum in JFM 2080-2099 relative to 1980-1999. Stippling indicates at least six out of the nine members agree on the sign of the anomalies
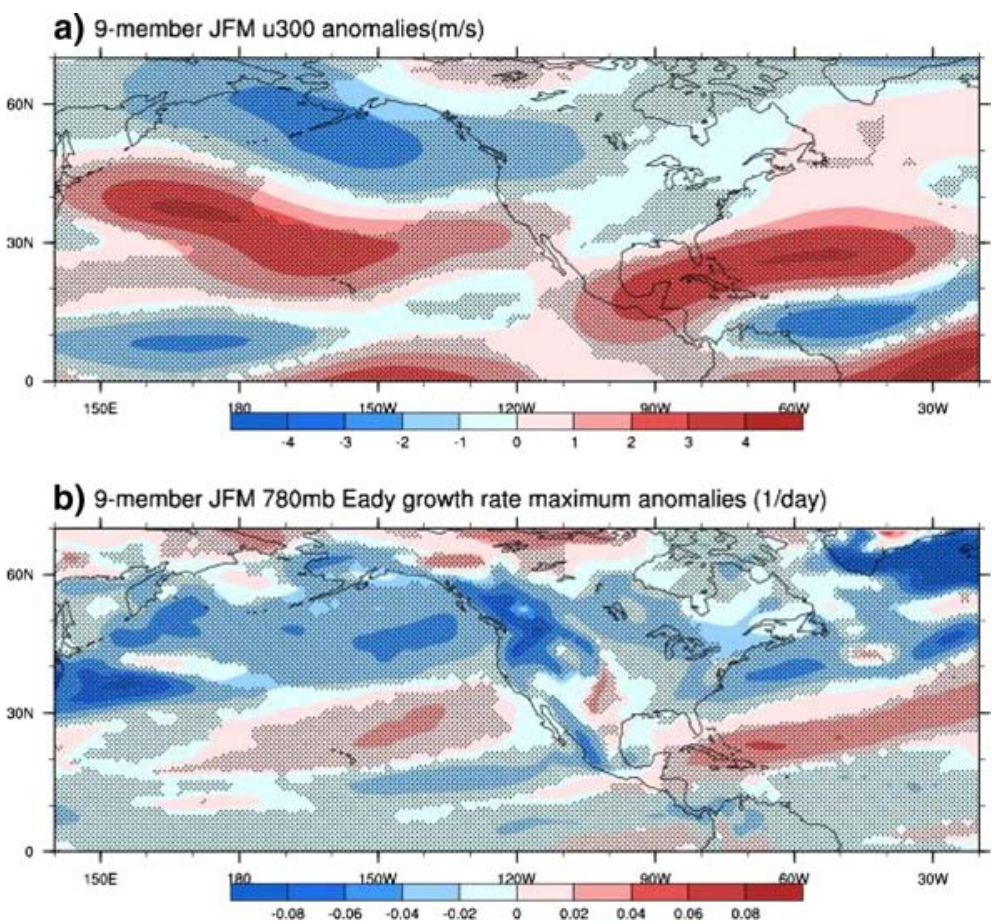

cyclones deeper than $980 \mathrm{hPa}$ shows positive correlations with the PNA and the NAO in the Pacific and the Atlantic sectors, respectively. Composite maps are also constructed for opposite phases of ENSO and the NAO. The results in general confirm that CCSM3 is able to produce the observed relationship between wintertime extratropical cyclone frequency and seasonal mean flow, which gives us confidence that the model can be used to study the future change.

In the twenty-first century, a single A1B realization shows that the cyclone frequency decreases in Alaska and on the East Coast, while it increases in the Great Lakes region and in the western US. The change in the cyclone frequency is closely linked to mean state changes in $300 \mathrm{hPa}$ zonal winds and the $780 \mathrm{hPa}$ Eady growth rate maximum. The other eight realizations support the one member regarding the mean state change on the US east coast and in Alaska, but an inconsistency is found in the Great Lakes region and in the western US.

These future changes are restricted to one coupled model. Although a large number of climate models participating in the IPCC AR4 agree on a poleward shift of the storm tracks under a warmer climate (Yin 2005, using an Eulerian approach), we found that the geographical pattern of the cyclone frequency anomalies exhibits large variations across the models after comparing some previous studies. For example, Bengtsson et al. (2006; Fig. 10) examined the future cyclone frequency change in the ECHAM5. The Atlantic storm tracks demonstrate similar weakening over the US East Coast as in the
CCSM3, but the pattern over the Pacific region differs: the storm activity is enhanced over almost the entire North Pacific Ocean north of $35^{\circ} \mathrm{N}$, and suppressed between $35^{\circ} \mathrm{N}$ and $25^{\circ} \mathrm{N}$.

The reduced cyclone frequency in Alaska and on the East Coast in the CCSM3 can be explained by weakened lower troposphere baroclinicity due to smaller meridional temperature gradient or land-sea contrast under global warming, but change on the West Coast is more intriguing. All nine realizations agree that there is a southeastward extension of the upper-troposphere Pacific jet stream, associated with enhanced baroclinicity in the mid-Pacific. This El Nino-like anomalous pattern could cause significant impacts on the West Coast and the southern Great Plains. Orlanski (2005) has tested storm track sensitivity to Pacific sea surface temperature and found the eddies generated or regenerated in the mid-Pacific tend to break cyclonically, reducing the eastern ridge amplitude in the Pacific-North America region. Although the A1B scenario demonstrates similar features, the cause could be more complicated than the tropical heating asymmetry (many GCMs including CCSM3 produce El Nino-like Pacific warming anomalies under greenhouse gas forcing, Meehl and Washington 1996; Teng et al. 2006b). Lacking sensitivity experiments, we are unable to separate the contributions from the Tropics and midlatitudes. Also, we have presented the linkage between the eddy activity and the mean state change focusing on how mean state can affect the eddies. Eddy-mean flow interaction is one of the most controversial issues in storm track dynamics (Chang 
et al. 2002), and the feedback between eddies and the mean flow has not been discussed here.

This study shows that even within a single model, the atmospheric mean state response can vary considerably in the midlatitude across different ensemble members. Statistics based on multi-member ensemble can quantify the uncertainty, but it is a big technical challenge to save high-frequency (e.g., 6-hourly) outputs from each individual ensemble member, especially for relatively highresolution models such as CCSM3. In addition, the large variations of cyclone tracking schemes make it difficult to compare results from various models. Automated tracking may also generate systematic errors, especially in cyclone lifetime. The relatively good agreement between change in cyclone frequency and the mean state in the upper-level zonal wind and lower-troposphere baroclinicity, as we have shown in this study, may allow using an Eulerian approach to study future changes in cyclone frequency. Such a shortcut may especially benefit multi-model intercomparsion work.

Acknowledgments We appreciate the valuable suggestions that have been provided by Jeffrey Yin. We would also like to thank the reviewers for their helpful comments. This research was supported by the Office of Science (BER), US Department of Energy, Cooperative Agreement No. DE-FC02-97ER62402. The National Center for Atmospheric Research is sponsored by the National Science Foundation.

\section{References}

Alexander M et al (2006) Extratropical Atmosphere-ocean variability in CCSM3. J Clim 19:2496-2525

Bengtsson L, Hodges KI, Roeckner E (2006) Storm tracks and climate change. J Clim 19:3518-3543

Blackmon ML, Wallace JM, Lau NC, Mullen SL (1977) An observational study of the Northern Hemisphere wintertime circulation. J Atmos Sci 34:1040-1053

Blackmon ML, Lee YH, Wallace JM (1984) Horizontal structure of $500 \mathrm{mb}$ height fluctuations with long, intermeditate and short time scale. J Atoms Sci 41:961-979

Blender R, Schubert M (2000) Cyclone tracking in different spatial and temporal resolutions. Mon Wea Rev 128:377-384

Collins WD et al (2006) The Community Climate System Model Version 3 (CCSM3). J Clim 19:2122-2143

Chang EKM, Lee S, Swanson KL (2002) Storm track dynamics. J Clim 15:2163-2183

Eichler T, Higgins W (2006) Climatology and ENSO-related variability of North American extratropical cyclone activity. J Clim 19:2076-2093

Greeve CZ, Pope VD, Stratton RA, Martin GM (2007) Representation of Northern Hemisphere winter storm tracks in climate models. Clim Dyn 28:683-702

Gulev SK, Zolina O, Grigoriev S (2001) Extratropical cyclone variability in the Northern Hemisphere winter from the NCEP/ NCAR reanalysis data. Clim Dyn, 17:795-809

Geng Q, Sugi M (2003) Possible change of extratropical cyclone activity due to enhanced greenhouse gases and sulfate aerosolsStudy with a high-resolution AGCM. J Clim 16:2262-2274
Hirsch M, DeGaetano A, Colucci S (2001) An East coast winter climatology. J Clim 14:882-899

Hodges KI (1994) A general method for tracking analysis and its application to meteorological data. Mon Wea Rev 122: $2573-2586$

Hoskins BJ, Valdes PJ (1990) On the existence of storm-tracks. J Atmos Sci 47:1854-1864

Hurrell JW (1995) Decadal trends in the North Atlantic Oscillation: regional temperatures and precipitation. Science 269:676-679

Hurrell JW, van Loon H (1997) Decadal variations in climate associated with the North Atlantic Oscillation. Clim Change 36:301-326

Hurrell JW, Hack JJ, Phillips AS, Caron J, Yin J (2006) The dynamical simulation of the Community Atmosphere Model Version 3 (CAM3). J Clim 19:2162-2183

Jung T, Gulev SK, Rudeva I, Soloviov V (2006) Sensitivity of extratropical cyclone characteristics to horizontal resolution in the ECMWF model. Q J R Meteorol Soc 132:1839-1857

Lambert SJ, Fyfe JC (2006) Changes in winter cyclone frequencies and strengths simulated in enhanced greenhouse warming experiments: results from the models participating in the IPCC diagnostic exercise. Clim Dyn 26:713. doi:10.1007/s00382-006-0110-3

Lau N-C (1988) Variability of the observed midlatitude storm tracks in relation to low-frequency changes in the circulation pattern. J Atmos Sci 45:2718-2743

Lindzen RS, Farrell BF (1980) A simple approximate result for maximum growth rate of baroclinic instabilities. J Atmos Sci $37: 1648-1654$

Kalnay E et al (1996) The NCEP/NCAR 40-year reanalysis project. Bull Am Meteor Soc 77:437-471

Meehl GA, Washington WM (1996) El Nino-like climate change in a model with increased atmospheric $\mathrm{CO}_{2}$ concentrations. Nature 382:56-60

Meehl GA, Washington WM, Santer BD, Collins WD, Arblaster JM, Hu A, Lawrence DM, Teng H, Buja LE, Strand WG (2006) Climate change projections for the twenty-first century and climate change commitment in the CCSM3. J Clim 19:25972616

Rogers JC (1997) North Atlantic storm track variability and its association with the North Atlantic Oscillation and climate variability of northern Europe. J Clim 10:1635-1647

Rudeva I, Gulev SK (2007) Climatology of cyclone size characteristics and their changes during the cyclone life cycle. Mon Wea Rev 135:2568-2587

Serreze MC (1995) Climatological aspects of cyclone development and decay in the Arctic. Atmos Ocean 33:1-23

Serreze MC, Carse F, Barry RG, Rogers JC (1997) Icelandic low cyclone activity: Climatological features, linkages with the NCAR and relationship with recent changes in the Northern Hemisphere circulation. J Clim 10:453-464

Simmonds I, Keay K (2000) Mean Southern Hemisphere extratropical cyclone behavior in the 40-year NCEP-NCAR reanalysis. J Clim 13:550-561

Sinclair MR (1997) Objective identification of cyclones and their circulation, intensity and climatology. Wea Forecast 12:591-608

Straus DM, Shukla J (1997) Variations of midlatitude transient dynamics associated with ENSO. J Atmos Sci 54:777-790

Teng H., Washington WM, Meehl GA, Buja L E, Strand GW (2006a) Twenty-first century Arctic climate change in the CCSM3 IPCC scenario simulations. Clim Dyn 26:601-616

Teng H, Buja LE, Meehl GA (2006b) Twenty-first-century climate change from a multi-model ensemble. Geophy Res Lett 33: L07706. doi:10.1029/2005GL024766

Trigo IF (2005) Climatology and interannual variability of stromtracks in the Euro-Atlantic sector: a comparison between ERA40 and NCEP/NCAR reanalyses. Clim Dyn 26:127-143 
Trenberth KE, Hurrell JW (1994) Decadal atmosphere-ocean variations in the Pacific. Clim Dyn 9:303-309

Wallace JM, Gutzler DS (1981) Teleconnections in the geopotential height field during the northern hemisphere winter. Mon Wea Rev 109:784-812

Yin $\mathbf{J}$ (2005) A consistent poleward shift of the storm tracks in simulations of twenty-first century climate. Geophys Res Lett doi:10.1029/2005GL023684
Zhang X, Walsh JE, Zhang J, Bhatt US, Ikeda M (2004) Climatology and interannual variability of Arctic cyclone activity: 19482002. J Clim 17:2300-2317

Zolina O, Gulev SK (2002) Improving accuracy of mapping cyclone numbers and frequencies. Mon Wea Rev 130:748-759 
Copyright of Climate Dynamics is the property of Springer Science \& Business Media B.V. and its content may not be copied or emailed to multiple sites or posted to a listserv without the copyright holder's express written permission. However, users may print, download, or email articles for individual use. 